\title{
RACIONALIDAD UNIVERSAL Y DEMANDAS LOCALES EN R.M. HARE Y K.-O. APEL
}

\section{Santiago N. Prono*}

Refiere Ernesto Garzón Valdés al hecho, que parece ser cierto, según el cual Heinrich von Kleist se pegó un tiro el 21 de Noviembre de 1811, en el lago berlinés de Wann porque, después de haber leído la Crítica de la Razón Pura de Kant, estaba convencido que era imposible lograr una fundamentación última del conocimiento del mundo ${ }^{1}$. En lo que a la moral respecta, puede decirse que también desde Kant la dificultad de lograr una fundamentación (justificación) racional de las normas se ha constituido en un problema permanente en el ámbito de la filosofía práctica sobre el cual vienen discutiendo los filósofos desde hace tiempo. Quienes participan de esta discusión suelen argumentar desde perspectivas diferentes, atribuyen muchas veces a las teorías rivales criterios dudosamente defendibles, o les imputan insuficiencias que resultan de una no muy exacta reconstrucción de los argumentos del otro.

En el presente trabajo me propongo considerar dos teorias que aceptan la posibilidad de basarnos en una concepción de la racionalidad práctica inherente a los enunciados morales, y de alcanzar un punto de vista moral universal. Estas dos teorías son las de R.M. Hare y K.-O. Apel, las cuales serán analizadas respecto de un aspecto puntual que es necesario tener en cuenta para todo intento de fundamentación racional de las normas morales. Me refiero a las condiciones fácticas en las cuales se pretenden aplicar tales normas, cuestión que a mi entender reviste una importancia no menor, que no debe perderse de vista.

\footnotetext{
* Licenciado en Filosofía de la Universidad Nacional del Litoral; santiagoprono@hotmail.com

${ }^{1}$ Garzón Valdés, E. “¿Puede la razonabilidad ser un criterio de corrección moral?”, en Bertomeu, M., Gaeta, R. y Vidiella, G.; Universalismo y multiculturalismo, Eudeba, Buenos Aires, 2000, pp. 177-210.
} 


\section{R.M. Hare y el prescriptivismo universal.}

1.1.

El prescriptivismo de Hare se vale de la lógica modal, y más específicamente de aquella parte de la misma que estudia y formaliza cuestiones relacionadas con la obligación, la permisión y las formas de argumentación o del razonamiento práctico en general; nos estamos refiriendo a la lógica deóntica. Es en este contexto del análisis metaético del lenguaje moral que recurre al término deber como un operador modal deóntico que rige prescripciones ${ }^{2}$. Dicho término constituye un ejemplo de la posibilidad de dar cuenta del modo en que ciertos sistemas de lógica se constituyen en modelos adecuados del lenguaje moral, nos advierte el autor. De hecho es en su opinión el ejemplo más simple de palabra típicamente empleada en un discurso moral o, para abreviar, la palabra moral; se trata de un término puramente formal. $\mathrm{Y}$ es este componente lógico del verbo deber que hace que toda vez que formulemos un juicio moral prescriptivo, estemos comprometidos a formular el mismo juicio ante situaciones similares en cuanto a sus características distintivas relevantes, y por lo cual tales enunciados resultan también universalizables. De este modo, y retomando el núcleo normativo de la ética kantiana, Hare ha pretendido justificar las dos características fundamentales del "moral point of view": la obligación y la imparcialidad. En tal sentido, propone que los términos del lenguaje moral tienen un significado, además de prescriptivo, universalizable también. Se trata de dos propiedades lógicas y formales del citado verbo necesario para expresar juicios prescriptivos.

A propósito de esto, cabe también señalar que el principio de universalización que el filósofo postula sostiene que cuando prescribo una acción que afecta a otro de cierta manera, dado que estoy prescribiendo para todas las situaciones similares a la mía, yo debo poder considerar imparcialmente los intereses de los involucrados (introducción de una tesis utilitarista).

Esta propuesta lo lleva a afirmar, en una primera instancia, que las decisiones morales que un agente debe tomar son una consecuencia de carácter lógico derivada de una norma abstracta; por lo cual no está exenta

${ }^{2}$ Hare, R.M., Ordenando la ética, Ariel, Madrid, 1999, p. 149. 
de problemas. Veamos por qué ya que nos permitirá introducirnos directamente en el análisis del tema que nos interesa. Para ello analizamos a continuación sólo un aspecto puntual.

De los enunciados prescriptivos se siguen -para Hare- imperativos universales $^{3}$, pero esta idea del autor resulta por lo menos dudosa ya que las prescripciones son supervinientes ${ }^{4}$, mientras que los imperativos no pueden serlo. Y ello porque según J. Raz, junto a otros filósofos oxonienses influenciados por H.L.A. Hart, estos no dan, y tampoco tienen por qué hacerlo, ninguna clase de razones que los respalden ${ }^{5}$. Se trata de órdenes, mandatos, pedidos, etc. que, dadas ciertas presuposiciones pragmáticas como ser la existencia de una sociedad cuyos miembros deciden regirse por las normas jurídicas, pretenden constituirse en razones, generalmente de tipo excluyentes, para la acción. En efecto, las normas lo son en virtud de que ellas tienen la pretensión de constituirse en un tipo especial de razones para actuar que se encuentran por encima de, es decir, superando y excluyendo a, las deliberaciones que los destinatarios de tales disposiciones puedan llevar a cabo. Es este último el aspecto fundamental por el cual quienes adhieren a la citada tradición caracterizan el concepto de autoridad.

En este problema propio del formalismo de la teoría se desconoce la necesidad de tener en cuenta también los aspectos característicos de las diversas comunidades, lo que ha provocado un desplazamiento de su postura lógico-semántica hacia concepciones que implican la incorporación de un cierto contenido sustantivo, pretendiendo introducir una tesis utilitarista. $Y$ aquí es donde entra la cuestión de tener en cuenta los aspectos específicos de las comunidades involucradas. En tal sentido, sostiene que "hay una afinidad entre la tesis del prescriptivismo universal, que reviste un

\footnotetext{
${ }^{3}$ Ibid., pp. 149-150.

${ }^{4}$ Esta es una característica que a los mismos les atribuye el autor y que consiste en suponer que siempre, ante un enunciado prescriptivo, podemos lógicamente dar cuenta de, o exigir, las razones que los respaldan, es decir: siempre podemos preguntar "¿por qué?"; además del hecho de que siempre podemos universalizar esa razón.

5 Véase para ello de J. Raz: Razón práctica y normas, Centro de Estudios Constitucionales, Madrid, 1991, y La ética en el ámbito público, Gedisa, Barcelona, 2001.
} 
carácter estrictamente lógico, y la concepción tradicional del utilitarismo" que, por supuesto, supone la maximización de los intereses que podrían tener los involucrados en un determinado contexto ${ }^{6}$. Pero ¿por qué lo dice? En verdad este intento de incorporación no resulta del todo adecuado. Lo que uno podría esperar es que Hare mostrara el modo en que ambos aspectos se presuponen mutuamente, pero lo cierto es que no lo hace; desde el punto de vista de la tesis semántica no hay estrictamente hablando punto de contacto alguno con el utilitarismo. No veo cómo el formalismo de su punto de vista podría dar lugar a un aspecto sustantivo del bien como el que plantea el utilitarismo. Se trata, si se quiere, de una cuestión de definición: la tesis lógica en cuestión plantea que ante situaciones similares debemos prescribir el mismo enunciado, es decir, ante la reiteración del antecedente, se aplica el mismo juicio prescriptivo, y nada más se necesita para explicar dicha tesis en este nivel de razonamiento práctico. En efecto, ¿cómo puede haber una relación supuestamente lógica de derivación (implicación) entre la pura formalidad de los enunciados prescriptivos, y el contenido sustantivo que a tales enunciados supuestamente también caracteriza?, es decir: ¿qué garantiza que de un enunciado moral prescriptivo, que presupone ciertas razones derivadas del carácter lógico del término "deber" que lo compone, se derive una tesis utilitarista que se caracteriza, no por la mera formalidad de tal planteo, sino por el contenido específico de los mismos? En realidad no hay nada en su tesis lógico-semántica que evidencie necesariamente la presencia de algún componente utilitarista. De hecho parecería haber un hiato entre estos dos tipos de planteos y, en consecuencia, esta apelación al utilitarismo podría ser interpretada como una suerte de explicación ad boc para solucionar las deficiencias de este enfoque formal, ya que no hay una razón que la justifique.

Ahora bien, aun aceptando la viabilidad de esta incorporación de la tesis utilitarista, que supone un intento de tener en cuenta y maximizar los deseos e intereses de los involucrados como una manera de contribuir a la universalidad de las normas morales (cosa que de por sí el enfoque lógicoformal no logra). Se plantea entonces la pregunta de cómo se conocen los deseos e intereses de los otros. Para esto último Hare apela a la idea de que

${ }^{6}$ Hare, R.M., Freedom and reason, Oxford University Press, Oxford, 1987, pp. 118, 124-125. 
es posible situarnos en el lugar del otro a través de las llamadas "transferencias interpersonales".

Basándose en un trabajo del Profesor Z. Vendler de 1976 titulado "A note to the Paralogisms"7, afirma que hay propiedades no-esenciales de las personas, y por eso sería posible sostener que, por ejemplo, mientras que la frase "Juan se imagina en la precisa situación de Pedro" es autocontradictoria pues implicaría ocupar dos lugares a la vez, para Hare la frase "yo soy Pedro" dicha por Juan no lo es. Dos son los supuestos en los que se basa. 1) utilizar la expresión "yo" no involucra la atribución de ninguna otra propiedad esencial más que la de ser una persona; vendría a ser algo así como el marco habitual al cual se adaptan todas las imágenes. A partir de esto sería posible afirmar sin contradicción "yo soy Pedro" aun cuando no lo sea. La idea aquí, según el filósofo, sería remarcar el carácter inalterable del término "yo", ya que no implicaría de suyo ninguna particularidad específica, propia de la personalidad del otro que supuestamente pasaría a ocupar. 2) Por otro lado se retrotrae Hare a algunas de las formas del "argumento por analogía", señalando que podríamos razonablemente suponer que tenemos experiencias de conciencia semejantes bajo condiciones similares ${ }^{8}$, para lo cual recurre a la figura del observador ideal que imparcialmente registraria la conducta de las personas. Así es como para los casos bilaterales en los que ambas partes ocupan distintas posiciones sería posible, a partir de la observación directa de los aspectos relevantes, tener un conocimiento completo de las preferencias de la otra persona.

Teniendo en cuenta estos supuestos, a su entender el argumento de las transferencias interpersonales quedaría completo y entonces podríamos situarnos absolutamente en el lugar del otro, es decir, como siendo él mismo. Y esto se relaciona con la tesis utilitarista, porque conocer los deseos e intereses de los involucrados es el criterio que debemos tener en cuenta para la formulación de enunciados prescriptivos que los satisfagan, y que sean por todos aceptados. En otros términos: no habría razón por la cual no

7 Hare, R.M.; Contemporary aspects of philosophy, Henley on Thames, Londres, y Oriel Press, Oxford, 1976, pp. 111-121.

${ }^{8}$ Hare, R.M., Moral thinking, Oxford University Press, Hong Kong, 1984, pp. 118119. 
aceptar la posibilidad de conocer las preferencias de los otros combinada con el requerimiento por el cual debemos universalizar nuestras prescripciones morales. Así es como para Hare este planteo respecto de la viabilidad de las transferencias interpersonales permitiría una progresión desde la aceptación de las prescripciones para las propias experiencias, a la aceptación de las mismas según las experiencias que tengo a partir de la posibilidad de estar en la posición de otros 9 .

Ahora bien, y respecto de 2), considero que apelar al citado "argumento por analogía" implica aceptar un presupuesto no suficientemente justificado. Y creo que es en este punto en donde la teoría de Hare, a pesar de lo que explícitamente sostiene en contra, incurre en algunos problemas relacionados, en última instancia, con una cierta noción del intuicionismo, y que por eso mismo no prueba adecuadamente. En efecto, vimos que el autor pretende afirmar que, a partir de la observación de la conducta de los otros, es posible ocupar sus lugares y conocer sus deseos $\mathrm{e}$ intereses de un modo inmediato, directo, y sin ninguna intermediación discursiva. Este procedimiento presupone también, como señala E. Tugendhat, una cierta base de psicologismo ${ }^{10}$. En tal sentido, el problema con el argumento de las transeferencias interpersonales, es que siempre existe la posibilidad de que la observación en cuestión implique una injustificada proyección de nuestra experiencia (ante las mismas situaciones y con el mismo aparente comportamiento), que en el fondo suponga una excesiva o defectuosa atribución de sentimientos; a fin de cuentas, "quien observa debe procurar ponerse al mismo tiempo en la situación de cada uno y comparar el peso de los diversos intereses del modo como se supone que cualquier otro los ponderaría a su vez"11. En este sentido creo que, en lo que a la determinación de los intereses, inclinaciones y experiencias de los demás refiere en base a la observación de la conducta, si bien es verdad que podemos arrojar cierta claridad sobre la cuestión fijando criterios con un mínimo de objetividad y trazando fronteras imaginarias por todos aceptadas, lo cierto es que nunca está de más que recordemos lo difícil que resulta someter (reducir) la conducta humana a esquemas simplificadores, como a las que puede dar lugar, a mi entender, esta cuestión de las transferencias

${ }^{9}$ Ibid., pp. 110, 108.

${ }^{10}$ Tugendhat, E., Lecciones de ética, Gedisa, Barcelona, 2001, p. 309.

${ }^{11}$ Ibid. 
interpersonales. Por supuesto que hay casos en los que todos estaríamos de acuerdo, y para los que estas consideraciones que venimos señalando no tendrían mayor relevancia. Pero ¿qué sucede en aquellos casos en los que la cuestión no es en absoluto algo evidente?, ¿presenta Hare en realidad, con esta idea de poder situarnos in propia persona en el lugar del otro, un método suficientemente justificado que asegure la imparcialidad de las aseveraciones que un supuesto observador ideal pueda plantear respecto de la subjetividad de otras personas? Creo que la respuesta es negativa. La perspectiva de un observador no puede dar cuenta del punto de vista interno que se necesita para conocer los deseos de los involucrados, como las transferencias interpersonales pretenden hacer. $\mathrm{Y}$ este es un aspecto de fundamental importancia ya que esta idea de Hare supone un punto de vista externo. Estoy de acuerdo en que tal observador puede registrar las regularidades de conducta observables y, después de un tiempo, y sobre la base de estas últimas, predecir con un aceptable grado de acierto la conducta normal de los individuos involucrados. Sin embargo, si se atiene realmente en forma rígida a este punto de vista externo, está claro que no podrá dar ninguna explicación de la manera en que tales individuos se comprenden a sí mismos a partir de los sentimientos que ellos mismos experimenten, cosa de la cual supuestamente las transferencias interpersonales pretenden dar cuenta. Además, y respecto del observador en cuestión, ¿qué seguridad tenemos de que el resultado que obtiene es idéntico al que obtendría cualquier otro que intente juzgar imparcialmente? Creo que por cierto muy pocas si pretendemos adoptar una concepción universalista, como el método de Hare al principio propone pero que, por esto mismo, no parece respetar. En definitiva, podemos ver que este procedimiento presupone una fuerte base tanto intuitiva como así también psicológica.

\section{2 .}

En función del objetivo que guía este trabajo, podemos decir que en verdad Hare no logra considerar adecuadamente la realidad concreta sobre la que se pretenden aplicar las normas morales racionalmente fundamentadas. Desde ya que su formalismo resulta insuficiente para ello; ahora bien, y aunque intenta incluir algún contenido que permita al agente aplicar dicho principio ante una situación dada, lo cierto es que 1) esto supone una incorporación ad boc del utilitarismo y, 2) el otro problema es que apela al procedimiento de las transferencias interpersonales para pretender dar cuenta de tales intereses, y la consecuente satisfacción de los 
mismos que una tal tesis utilitarista implica. En este sentido supone que los involucrados formarían, en este experimento mental, una población homogénea de "yoes" que tendrían las características empíricas de mi propio yo mediante lo cual este filósofo parece introducir subrepticiamente, como señalamos, y aunque sea de un modo indirecto, una cierta concepción del intuicionismo que su postura critica. Por ello me parece que es muy difícil sostener que con esta concepción de su teoría ética Hare logre dar cuenta del punto de vista de los involucrados.

\section{K.-O. Apel y la ética discursiva.}

2.1.

La concepción de la ética discursiva que nos presenta este filósofo para la fundamentación de las normas, no cae en el tipo de inconvenientes en que incurre el enfoque anterior. Desde el comienzo mismo esta propuesta se divide en dos; parte A de fundamentación, y parte B de aplicación. En la primera se hace evidente el carácter reconstructivo de su método pues, por empezar, supone una elucidación de los presupuestos inherentes a la racionalidad comunicativa que se constituyen en condición de posibilidad del uso del lenguaje necesario para el planteo de toda pretensión de validez intersubjetiva. Y lo cierto es que de esta reflexión pragmático-trascendental resulta un principio ético presupuesto en toda argumentación (que es universalmente válido independientemente del tema en cuestión). La propuesta apeliana introduce una transformación de la filosofía de la conciencia, construida sobre la base de la relación sujetoobjeto, y sostiene, por el contrario, la necesidad de concebir una relación de tipo sujeto-cosujeto. Un sujeto solo, en base a sus funciones de conciencia (Kant - Husserl), no está capacitado para la tematización de "algo como algo" pues tal cosa sólo puede especificarse a partir de una clarificación reconstructiva de los presupuestos comunicativos del entendimiento intersubjetivo por medio del lenguaje $\mathrm{e}^{12}$. $\mathrm{Y}$ es a partir del hecho de elucidar tales presupuestos que estamos también ante las condiciones de posibilidad para la resolución de las pretensiones de validez.

${ }^{12}$ Apel, K.-O., Semiótica filosófica, Almagesto, Buenos Aires, 1994, pp. 122-123. 
Así es como para Apel el principio del discurso, norma básica o metanorma de procedimiento para la fundamentación de todas las normas, según el cual para todo conflicto de intereses se debe recurrir al discurso práctico $^{13}$, implica exigencias de veracidad y rectitud moralmente relevantes para los actos asertóricos en cuanto actos comunicativos. De hecho tales exigencias implican que todo aquél que argumente seriamente, acepta necesariamente también determinadas condiciones normativas de la validez intersubjetiva (lo que supone una anticipación contrafáctica de una comunidad ideal de comunicación). Es decir: en toda argumentación que se lleve a cabo necesariamente deben respetarse ciertas "reglas" que la hacen posible, las que ciertamente revisten un carácter de honestidad y respeto recíproco. En tal sentido se evidencia el reconocimiento mutuo de todos los miembros (o sus representantes) como participantes de una discusión con igualdad de derechos, y este es ya un principio moral de justicia que se puede formular como condición de posibilidad de un discurso válido, lo que resulta una presuposición evidentemente necesaria de toda comunidad de argumentación. Debe considerarse también, como dijimos, que el método discursivo (en esta parte A) da cuenta de un nivel que no puede ya ser fundamentado por principio pues adquiere un carácter trascendental. Esto significa que es condición de posibilidad de toda fundamentación ya que incluso para objetarlo es necesario argumentar, lo que a su vez evidencia el carácter de irrebasabilidad (Unbintergebbarkeit) del método en cuestión. Así es como estamos ante una propuesta de fundamentación reflexiva de carácter pragmático-trascendental, cuya elucidación de los presupuestos de toda argumentación da cuenta del reconocimiento de la validez de la ley moral (introducción de una perspectiva apriorística).

Por otro lado, debe quedar claro también que en el ámbito de la ética discursiva, las diversas posturas que se adopten, deben necesariamente estar siempre abiertas a discusión para las objeciones que en un sentido crítico puedan plantearse, y siempre que las mismas estén fundamentadas. En efecto, el contenido de las normas situacionales siempre es revisable, por lo cual no deberíamos negarnos a discutir nuevamente ni a revisar los

${ }^{13}$ En el sentido de una forma de diálogo en la que se cuestionan pretensiones de validez y en la que sólo se emplean argumentos y contraargumentos racionales. (cfr. Maliandi, R., "Conceptos y alcances de la 'ética del discurso' en Karl-Otto Apel", en Tópicos, $\mathrm{N}^{\circ} 10,2002$, p. 63). 
principios o creencias establecidas. Esto significa que no podemos afirmar una validez definitiva y sin excepciones de las normas específicas que se establezcan mediante el procedimiento del discurso.

Apel concibe a la norma básica antes mencionada como idea regulativa del actuar humano en comunidad para la realización aproximativa de la comunidad ideal en la real; pero no supone utópicamente la existencia fáctica de las exigencias normativas como ya dadas en la comunidad real. Para Apel, la función de esta idea regulativa es la de un procedimiento para la crítica de las prácticas y para la orientación en el camino de nuestros intentos éticos de mejorar la sociedad y disminuir la diferencia entre la comunidad real e ideal de comunicación ${ }^{14}$.

2.2.

Con esto he intentado dar cuenta fundamentalmente del aspecto, si se quiere, más abstracto de la ética discursiva de Apel (y ello se debe al hecho de que es en el mismo en el que me baso para lo que sigue). El autor también plantea la necesidad y urgencia de una ética de la responsabilidad solidaria (Verantwortungsethik) por las consecuencias y sub-consencuencias de las acciones del hombre en el contexto de sus particulares sistemas de autoafirmación, y cuya evaluación delega en el discurso práctico de los afectados con ayuda de los expertos debidamente capacitados, quienes contribuyen a la determinación del contenido específico de las normas situacionales (de este modo se hace valer la interpretación y valoración autónoma de las situaciones por parte de los propios sujetos morales). A partir de esto puede decirse entonces que intenta el filósofo una suerte de mediación (Vermittlung) entre la validez universal de los principios éticos a los que se llega a través de una reconstrucción pragmático-trascendental respecto del uso comunicativo del lenguaje (el cual se evidencia en la parte A de fundamentación), y las contingencias socio-históricas específicas sobre la que tales normas se pretenden aplicar (parte B).

En la parte B, de aplicación, se evidencia que el apriorismo de su postura resulta compatible con una concepción realista y no ingenua pues

${ }^{14}$ Apel, K.-O., “' $A$ priori de la facticidad y a priori de la idealización'. Opacidad y transparencia", en Blanco Fernández, D., Pérez Tapias, J., Sáez Rueda, L. (eds.), Discurso y realidad. En debate con K-O. Apel, Trotta, Madrid, 1994, p. 258. 
acepta la posibilidad de recurrir a procedimientos estratégicos, aunque bajo la condición de promover la institucionalización progresiva del principio del discurso para solucionar los conflictos de intereses (esto lo analizamos en breve). Sin embargo, el tema es que, en mi opinión, al menos una parte de su teoría se estructura sobre la base de un, por momentos, excesivo privilegio por los aspectos más abstractos de la misma, y de allí la confianza respecto de la suficiencia de su planteo para resolver los diversos conflictos de la comunidad real de comunicación. (En lo que sigue, me referiré a los aspectos más "abstractos" en el sentido de sus reiteradas aseveraciones que se enmarcan en el contexto de la comunidad ideal de comunicación.). Dos son las cuestiones que rescataré de su planteo para intentar justificar esta observación.

En primer lugar, y teniendo en cuenta la posibilidad de recurrir, en ciertas circunstancias, a la racionalidad estratégica ( $\mathrm{y}$ hacer uso de la mentira, el fraude, la violencia, etc.) ${ }^{15}$, el problema sería que no se especifican suficientemente ciertos criterios normativos que restrinjan las medidas que se adopten. Analicemos esta concepción para ver adónde nos lleva ${ }^{16}$. La cuestión aquí no sería tanto el hecho de que, llegado el caso, se brinde la posibilidad de recurrir a los medios que fueren para la obtención del fin buscado, cosa que ante situaciones de emergencia, y por cuestiones de responsabilidad, bien podemos aceptar (imagínese para justificar esto el ejemplo que se crea conveniente). Sino que se acepte esto sin demasiadas restricciones normativas que limiten seriamente la posibilidad de reducir la moralidad al propio interés estratégicamente calculado. El punto es que, a

15 "Por ejemplo en el caso de la confrontación con un criminal, o con una organización como la Gestapo, [los sujetos morales] no podría renunciar a la mentira, el fraude, e incluso al uso de la fuerza, sino que deberían intentar actuar estratégicamente de modo adecuado a la situación, de forma que la máxima de su acción pudiera considerarse como una norma susceptible de consenso, sino en un discurso real, sí al menos en uno ideal imaginario de todos los afectados de buena voluntad" (Apel, K.-O., Teoría de la verdad y ética del discurso, Paidós, Barcelona, 1991, pp. 182-183).

${ }_{16}$ Por lo demás, algo parecido a nuestro planteo (respecto de esta cuestión específica que a continuación analizamos) parecen sostener R. Maliandi (cfr. Tópicos -cit.- pp. 71-72) y D. Michelini (cfr. Apel K.-O., Cortina A., De Zan J. y Michelini D. -eds.- Ética comunicativa y democracia, Crítica, Barcelona, 1991, p. 331). 
mi entender, esto tal vez daría pié a que la teoría incurra en determinados contraejemplos que podrían debilitarla seriamente. A propósito de esto, la cuestión se complica en la medida en que, en el contexto de esta ética, no debe permitirse la acción que rechace el progreso hacia el fin moral al que la misma tiende, como es aspirar a la mayor aproximación posible a la instauración de la comunidad ideal de comunicación. Es necesario, pues, identificar más explícitamente ciertos criterios normativos que nos permitan, además de justificar y orientar su aplicación (como hace Apel), también restringir o regular adecuadamente la momentánea suspensión de la aplicación de los principios éticos. En otros términos, pienso que si en determinadas circunstancias se brinda la licencia de proceder como se crea conveniente para intentar alcanzar dicho objetivo, entonces deberían establecerse más específicamente los límites de tal proceder, y no sólo mencionar como condición el promover la efectivización de los discursos prácticos. Esto es ciertamente problemático. Obviamente, graves son las consecuencias que de esto podrían seguirse.

Apel, entonces, no parece preocuparse demasiado por especificar esta clase de límites al proceder estratégico, cuestión que se derivaría de la excesiva confianza en su teoría para resolver los problemas de la comunidad fáctica de comunicación. $Y$ lo cierto es que se trata de una confianza en los aspectos más abstractos de la misma pues, como veremos, son estos los que determinan aquella clase de procedimientos.

Una segunda consideración refuerza esta presunción, y está estrechamente ligada a lo anterior. En efecto, es pertinente señalar que según estas últimas aseveraciones, este planteo implicaría una fuerza de convicción suficiente para proceder de acuerdo a los principios que caracterizan a la comunidad ideal. Afirma Apel que, por ejemplo en las condiciones institucionales de los Estados democráticos de derecho que efectivamente funcionan, pero también cuando hay que proceder de acuerdo con la racionalidad estratégica porque la situación así lo exige, "la aplicación de la norma fundamental de la ética discursiva [...] es completamente exigible"17. Se trata, según nuestro filósofo, del "reconocimiento de un compromiso exigido de la voluntad a favor del valor $\mathrm{u}$

${ }_{17}$ Apel, K.-O., Una ética de la responsabilidad en la era de la ciencia, Almagesto, Buenos Aires, 1990, p. 42. 
objeto de la realización de las condiciones de aplicación del principio ético del discurso", y así sostiene que "de la ética se deduce un principio del deber obligatorio en todo momento, y que obliga a un compromiso, resistente a la frustración, a favor del progreso moral"18. En tal sentido leemos también que si no están dadas las condiciones colectivas de aplicación de la norma básica de la ética discursiva, entonces, como vimos, aquellos que hayan logrado comprender la validez universal del principio ético del discurso, están obligados a proceder de acuerdo con la racionalidad estratégica para dominar adecuadamente la situación mediante soluciones de emergencia (recurriendo a los medios que fueren). También en otros lugares podemos encontrar este tipo de aseveraciones, pero la pregunta que surge y que es necesario responder, es: ¿por qué habría de ser así?, ¿por qué la anticipación contrafáctica de la comunidad ideal de comunicación, siempre presupuesta en todo ejercicio de la racionalidad argumentativa, debe ser sostenida por una motivación realmente eficiente de la dinámica del proceso de aprendizaje y de la racionalidad a largo plazo? ${ }^{19}$. Por supuesto, no se trata de objetar aquí que Apel intentaría pasar del campo de la fundamentación racional al campo de las acciones como una consecuencia directa o necesaria, sino de señalar que plantearía estas cuestiones a partir del privilegio que otorga a los aspectos más abstractos de su teoría, y adoptando en base a los mismos una excesiva confianza respecto de la suficiencia de su método para solucionar los problemas de la comunidad real (aun en las situaciones de emergencia en las que es necesario recurrir a la racionalidad estratégica), pues entiendo que, de un modo preponderante, tales aspectos son los que esto último permitirían $^{20}$.

${ }^{18}$ Apel, K.-O., Teoría de la verdad y ética del discurso, Paidós, Barcelona, 1991, p. 183.

${ }^{19}$ Cfr. Apel, K.-O., Penser avec Habermas contre Habermas, París, Editions de l'Éclat, 1990, p. 15. Los subrayados son míos.

20 Téngase en cuenta, por ejemplo, cuando recurre al principio C de complementación (respecto del principio de universalización habermasiano para la fundamentación de las normas). Con este principio aspira a colaborar en las condiciones de aplicación de los discursos prácticos, y aun cuando el mismo deba tener en cuenta las condiciones situacionales contingentes, afirma que es de carácter formal a priori y, en último término, consensuable en el sentido de la fundamentación última pragmático-trascendental. 
Por otro lado, creo que tal vez es el excesivo privilegio por parte de Apel a este tipo de cuestiones que venimos señalando el que habría llevado a algunos de sus interlocutores, como en el caso de R. Maliandi, a sostener que Apel "no alcanza a distinguir suficientemente las estructuras conflictivas de la realidad social, estructuras que no sólo determinan conflictos concretos contingentes, sino que permanecen -como un a priori- más allá de la solución de estos"'21.

De todos modos, y más allá de esta última crítica, creo que se deberían considerar más estos aspectos para que toda la teoría no aparezca como otorgando un excesivo privilegio a cuestiones abstractas. Adoptar tal punto de vista es necesario, qué duda cabe. Pero no se debería por ello admitir una perspectiva que por momentos parezca privilegiar excesivamente tales cuestiones. Por eso la necesidad de incorporar otra perspectiva que compense estas falencias.

\section{Comunidad ideal de comunicación y facticidad histórica: acerca de la posibilidad de su complementación.}

Vemos así que, si vale la analogía, la propuesta apeliana de la ética discursiva va de arriba bacia abajo, pero a mi entender en ciertos momentos se queda demasiado en aquella primera instancia. Por eso entiendo que sería conveniente que se complemente con otra propuesta que, siempre en el contexto del paradigma de la intersubjetividad como el medio más adecuado para la fundamentación de todas las pretensiones de validez, siempre

Asimismo, y de acuerdo con el privilegio por los aspectos más abstractos de su teoría, también sostiene Apel que en las situaciones de emergencia en las que es necesario apelar a la racionalidad estratégica, las medidas que se adopten deben estar determinadas por las reglas de juego fundamentadas en la línea de la comunidad ideal de comunicación. Cfr. Apel, K.-O., "Límites a la ética discursiva?", en Cortina, A.; Razón comunicativa y responsabilidad solidaria, Sígueme, Salamanca, 1995, pp. 250261.

${ }^{21}$ Maliandi, R., “Conceptos y alcances de la 'ética del discurso' en K.-O. Apel” (cit.), pp. 69-70. 
revisables y falibles, vaya en la dirección contraria. Y creo que en este sentido se torna sumamente interesante la postura de su amigo, J. Habermas ${ }^{22}$.

Ciertamente, Apel presenta a la ética discursiva con el sesgo propio de su empeño fundamentador de tipo pragmático-trascendental, y por la valorización de este aspecto resulta adecuada su postura. Ahora bien, me parece que los inconvenientes que venimos señalando en nuestro filósofo podrían atenuarse a partir, entonces, de una suerte de complementación con la postura de Habermas, que por cierto se opone a tal clase de fundamentación adoptando, por el contrario, una perspectiva más volcada al aspecto socio-histórico, y por lo cual otorgaría una mayor base empírica a la perspectiva apeliana sobre la cual poder sustentarse. Como ya anticipamos, se trata de una cuestión que no debería dejarse de lado en ninguna propuesta de fundamentación de las normas morales.

Afirma Habermas que el mundo de la vida (Lebenswelt) constituye el lugar originario de la racionalidad comunicativa sobre la base de la cual poder reconstruir las reglas y las condiciones de validez del discurso, tanto teórico como, fundamentalmente, moral ${ }^{23}$. En su opinión, este contexto de algún modo impediría a los agentes comunicativos adoptar una posición extramundana en su tarea de interpretación; y así, en tanto horizonte o trasfondo a partir del cual se actúa comunicativamente, el mundo de la vida, podríamos decir nosotros, es la condición de posibilidad de las diversas

22 Presentamos lo que sigue a modo de propuesta, cuya viabilidad debería por supuesto profundizarse más aún en una posterior etapa de investigación. En este sentido, aquí sólo nos proponemos mostrar de la postura de este filósofo lo suficiente como para ver que podría complementarse con la de Apel, y así contribuir a solucionar los problemas que esta presentaría. En relación con lo que al respecto sugerimos, puede también consultarse de J. De Zan, por ejemplo, "Ética, derecho y política en Karl-Otto Apel y Jürgen Habermas (contribución a la problemática de 'justicia y eficiencia')" en Eficiencia y justicia social. Desafios a América Latina, ICALA, Río Cuarto, 1992.

${ }^{23}$ Es importante aclarar de entrada que esta idea del "mundo de la vida" no debe interpretarse en términos exclusivamente culturalistas, pues comprende también experiencias subjetivas y prácticas sociales e individuales. Cfr. Habermas, J., Teoria de la acción comunicativa (II), Taurus, Madrid, 1987, pp. 193-194; y también con McCarthy, T., La teoría critica de Jüngen Habermas, Tecnos, Madrid, 1987, p. 465. 
formas que puede adoptar el entendimiento intersubjetivo ${ }^{24}$ (distinto es el caso de Apel que, como vimos, apela al concepto de comunidad ideal de comunicación como criterio para guiar la implementación de la racionalidad estratégica con el fin de posibilitar tal entendimiento). No por casualidad, como se sabe, es Habermas reticente a hablar de concepciones "trascendentalistas" para la fundamentación de las normas. En tal sentido, mientras que aquel, a partir de la reconstrucción de las condiciones pragmáticas de posibilidad y de validez del discurso que constituyen la instancia última de justificación, habla de "pragmática trascendental", en el caso de Habermas, por el contrario, habría una prescindencia de este último término por sus connotaciones apriorísticas, acentuando en cambio, como dijimos, la conexión de su propuesta reconstructiva con una concepción caracterizada por un marcado sesgo sociológico.

En efecto, cree este filósofo que las ideas morales desconectadas de la eticidad concreta de la vida cotidiana, no cuentan sin más con la fuerza motivacional necesaria que haga también eficaz, en la práctica, los juicios morales. De hecho, mientras que Apel en ciertas circunstancias señala, como vimos antes, la obligación y el compromiso de proceder de acuerdo con los principios fundamentados en la línea de la comunidad ideal de comunicación, en el caso de Habermas, por el contrario, se niega que pueda darse la obligatoriedad "moral únicamente a partir de la coacción trascendental, por decirlo así, de los presupuestos inevitables de la argumentación" 25 . Así es como adhiere a una suerte de "trascendentalismo débil" en el marco del cual atribuye a los discursos morales no sólo una debilidad cognitiva, debido a la inexistencia de criterios institucionales independientes o externos en función de los cuales poder determinar si una decisión se produjo o no conforme a derecho, sino también una debilidad motivacional. Según Habermas, es necesario compensar estas debilidades de la moral en ciertos casos con la fuerza vinculante que implica el derecho coercitivo moralmente justificado, y por eso es necesario un acoplamiento con el poder de sanción estatal". Habría entonces una "racionalidad procedimental imperfecta o incompleta" de los discursos morales. De este

${ }^{24}$ Habermas, J., Teoría de la acción comunicativa (II) (cit.), pp. 192-194.

${ }^{25}$ Habermas, J., La inclusión del otro, Paidós, Barcelona, 2004, p. 77.

${ }^{26}$ Habermas, J., Escritos sobre moralidad y eticidad, Paidós, Barcelona, 1991, pp. 163166. 
modo, y por lo menos desde 1983 cuando aparece Moralbewusstsein und kommunikatives Handeln, intenta este filósofo despegarse cada vez más de todo proyecto de fundamentación última de las normas morales erigido sobre la base de perspectivas trascendentalistas, que además reconozca como inherentes a las reglas argumentativas ciertos principios universales de carácter moral 27 .

En concordancia con esto último que venimos señalando, es necesario demostrar entonces que es, fundamentalmente, en las estructuras del mundo de la vida donde se libera un potencial de racionalidad que radica en el actuar comunicativo de la praxis cotidiana misma ${ }^{28}$. Por eso entiendo que parecería Habermas proponer una mayor valoración de la dimensión fáctica de la comunidad discursiva, y si bien parece hacerlo a costa de un marcado (más bien excesivo) sesgo socio-empírico que desconocería los principios morales universales inherentes al discurso ${ }^{29}$ (que en alguna medida son para Apel su condición de posibilidad), ello evidenciaría la viabilidad de complementarse con la propuesta de fundamentación de este último. Por esto es que podemos decir que cada uno adhiere a aquello que en el otro falta. En tal sentido, como ha reconocido Apel, las investigaciones de Habermas en el campo de la pragmática del lenguaje y de la acción comunicativa, vienen a tender un puente entre las teorías de la acción social y el punto de vista moral de las éticas deontológicas, sin el cual la moralidad carecería de la posibilidad de inserción efectiva en la estructura de la interacción humana y de la realidad social, y la ética discursiva quedaría flotando en el aire como una teoría típicamente alemana ${ }^{30}$.

Teniendo en cuenta, entonces, esta excesivamente breve reseña de la postura de Habermas, puede decirse que hay en este un marcado intento por

${ }^{27}$ Cfr. Moralbewusstsein und kommunikatives Handeln, Frankfort, Suhrkamp, 1983, pp. 109 ss., (cit. en Apel, K.-O., Penser avec Habermas contre Habermas -cit.-, p. 16).

${ }^{28}$ Habermas, J., "¿Qué es lo que hace a una forma de vida ser "racional'?", en Aclaraciones a la ética del discurso, Trotta, Madrid, 2000, pp. 48-49.

${ }^{29}$ Habermas, J., La inclusión del otro (cit.), p. 76, cfr. Facticidad y validez, Madrid, Trotta, 2001, pp. 172-174. Cabe aclarar que en estos pasajes, concibe Habermas al principio del discurso como valorativamente neutral.

${ }^{30}$ Cit. en J. De Zan, Panoramas de la ética continental contemporánea, Akal, Madrid, 2002, p. 103. 
recuperar el horizonte del mundo vital. Esto, precisamente, es lo que a mi entender, y a pesar de sus esfuerzos, falta en la postura de Apel para que su enfoque de la ética discursiva cierre adecuadamente. De este modo, estaríamos ante un enfoque que podemos tenerlo en cuenta, con los recaudos del caso y sin adherir plenamente al mismo, para cubrir algunas de las carencias que en la ética discursiva de Apel se presentan. En otros términos, pienso que, quizá, el análisis reconstructivo habermasiano de los presupuestos de la interacción comunicativa del mundo de la vida contribuya al sostenimiento fáctico que se necesita para el apriorismo trascendental de la ética discursiva de Apel, otorgándole una mayor base empírica sobre la cual sostenerse. Este, me parece, sería el aporte fundamental que desde esta perspectiva podemos señalar. Por eso creo que los planteos de ambos autores, antes que contraponerse, más bien se complementarían. No obstante ello, está claro que profundizar en esta vía de investigación aquí propuesta sería, como dijimos, el próximo paso.

\section{Consideraciones finales.}

A lo largo de este trabajo hemos analizado dos enfoques específicos desde los cuales se pretende llegar a una fundamentación racional de las normas morales, pero lo hemos hecho desde una perspectiva puntual que tiene que ver con la necesidad de tener en cuenta las características específicas de la realidad histórica, aunque sin renunciar a la posibilidad de dar con un punto de vista moral universal.

Por el lado del enfoque monológico de R.M. Hare, vimos que parte desde una perspectiva metaética analizando el significado del verbo "deber" y adoptando una concepción lógico-semántica por la cual sostiene que "yo debo" se sigue de "se debe"; de este modo pretende, infructuosamente a mi entender, derivar imperativos a partir de enunciados morales prescriptivos. Ahora bien, hemos visto que no es posible adoptar una concepción estrictamente lógico-formal pues, además, desconoce absolutamente la importancia del contexto socio-histórico. Por ello debe acudir a los intereses de los involucrados pretendiendo incorporar una tesis utilitarista, lo que sí daría cuenta de una estrecha consideración de las demandas particulares de las diversas comunidades involucradas. Sin embargo, esto también implica ciertos inconvenientes en la medida en que a) no tiene por qué haber, a diferencia de lo que sostiene, una relación de "afinidad" entre la citada tesis 
formal y la tesis utilitarista, y por lo cual el filósofo termina introduciendo de contrabando a esta última en la medida en que no justifica tal procedimiento, $\mathrm{y}$ b) las transferencias interpersonales a las que recurre para sostener al utilitarismo evidencian la adhesión, al menos de modo indirecto, a cierta forma de intuicionismo por pretender ponerse en el lugar del otro a partir del experimento mental que consiste en aceptar la supuesta objetividad de un observador ideal que, de un modo directo e inmediato, registraría las conductas de los individuos asignándoles determinados deseos e intereses; cuestión esta que, en un intento de fundamentación racional como el que pretende plantear, no es posible aceptar.

Por el lado del enfoque discursivo que K.-O. Apel nos presenta, vemos un claro intento por acercarse a la comunidad real de comunicación; además está claro que constituye una perspectiva más coherente de fundamentación. De hecho, yo acepto la posibilidad de fundamentar un criterio normativo para la eticidad vigente en el mundo de la vida sobre la base de una pragmática trascendental que reconstruya las presuposiciones morales fundamentales, que son condición de posibilidad y de validez de todo discurso, y respecto de las cuales es imposible, so pena de incurrir en una autocontradicción performativa ${ }^{31}$, retroceder por detrás de las mismas (irrebasabilidad). En este sentido, puede decirse, la comunidad ideal de comunicación, junto con la idea de consenso que esta implica, es, desde el punto de vista de su aceptación contrafáctica, ciertamente real.

Sin embargo, creo que es necesario, no obstante, un mayor acercamiento del que concibe Apel a la comunidad real de comunicación o, mejor dicho y para ser más específicos, no debería basarse preponderantemente en los aspectos más abstractos de su teoría, tal como en algunas ocasiones podemos apreciar; por eso la necesidad de que se complemente con una perspectiva más sociológica o empírica de la cuestión. Al final de cuentas, él mismo sostiene que, a pesar de sus esfuerzos, hay aún muchos problemas por resolver en relación con la posibilidad de

31 Utiliza este término Apel para referirse a la dimensión pragmática del lenguaje en la cual, en una misma proposición, se niega lo que se está afirmado o bien, a la inversa, se afirma lo que se niega. Consecuentemente, en este tipo de proposiciones puede mostrarse que se recurre al principio que está en tela de juicio. Cfr. Apel, K.O., Estudios éticos, Alfa, Barcelona, 1986, p. 205 (nota al pie N 51). 
interrelacionar el presupuesto racional de un a priori ideal (el de la comunidad ideal de comunicación siempre anticipada en todo ejercicio de la razón), y el a priori de la facticidad, esto es, la dependencia de dicho ejercicio con respecto a la existencia de una comunidad real e histórica de comunicación. No por nada este ha sido uno de los motivos centrales de toda su filosofía 32 .

\title{
Resumen
}

En este artículo se analiza un aspecto específico de dos de las más importantes teorías éticas contemporáneas para la fundamentación racional de las normas morales: el prescriptivismo universal de R.M. Hare, y la ética discursiva del filósofo alemán Karl-Otto Apel. Teniendo en cuenta la necesidad de establecer siempre una mediación entre la ética universal de principios, y los contextos históricos concretos de las comunidades que aplican dichas normas, se aborda esta última cuestión en las teorías de ambos filósofos. En el caso de Hare, además de la dificultad propia del formalismo que adopta, no puede dar cuenta de los problemas en cuestión en la medida en que, por un lado, la incorporación del utilitarismo que para este requerimiento propone no está justificada y, por el otro lado, con el procedimiento de las transferencias interpersonales es difícil conocer los deseos e intereses de las personas por la imposibilidad de ocupar el lugar del otro. En relación con Apel, el autor considera que, aunque propone una tesis más coherente, en realidad no tiene en cuenta adecuadamente los problemas de justificación de las decisiones y de la aplicación de los principios en las situaciones históricas.

Lo antes mencionado plantea la necesidad de considerar la viabilidad de complementación con la concepción habermasiana de la ética discursiva.

Palabras clave: "Hare”, "Apel”, "Habermas", "universalismo", “contextos históricos de aplicación"

\begin{abstract}
This article studies one specific aspect of two of the most important contemporary ethical theories for the rational foundation of morals norms: R. M. Hare's universal prescriptivism, and the discursive ethics of the German philosopher Karl-Otto Apel. In this way, and bearing in mind the necessity of always establishing a
\end{abstract}

32 Apel, K.-O., Discurso y realidad. En debate con K.-O. Apel (cit.), pp. 253-254. 
mediation between the universal ethics of principles, and the concrete historical contexts of the communities which apply the aforementioned norms, this last question is studied in the theories of both philosophers. In Hare's case, besides the inherent difficulty of the formalism he adopts, he cannot account for the problems indicated, inasmuch as, on the one hand, the incorporation of the utilitarianism that he proposes for this request is not justified and, on the other hand, with the method of interpersonal transferences, it is difficult to get to know the people's desires and interests, because of the impossibility of putting oneself in the other's place. As regards Apel, although he proposes a more coherent thesis, he does not in fact appropriately take into account the problems of the justification of decisions, and of the application of principles to historical situations. All these issues, pose the necessity of considering the feasibility of complementation with Habermas's conception of discursive ethics.

Key words: "Hare", “Apel”, Habermas", "Universal ethics of principles", "historical contexts of application" 